\title{
CORNEAL PITTING
}

BY

Lieut.-Col. H. Herbert, I.M.S. (Retd.)

IN the January, 1935, issue of the Brit. Jl. of Ophthal., Dr. Busacca, of Brazil, has shown photo-micrographs of sections that, to his mind, embody the essential features of the upper marginal corneal depressions of old trachoma, which, owing to MacCallan's kindly insistence, have become known as "Herbert's pits."

Rather deep, localized proliferation of epithelium was much more in evidence than surface depression, which was minimal. But there was too much cellular infiltration from recent trachomatous recrudescence, for one to be able to recognize any close relationship between epithelial downgrowth and supporting corneal lamellae.

The contribution is very acceptable, though illustrating only one phase and one grade of a trachomatous development, seen not infrequently in old days in India.

From the text of Busacca's paper it is evident that some objection to the scope or extent of his claim has been raised by Pascheff. Bearing upon this question I should like to make some observations supplementing my sole published report on trachomatous pitting. That brief report was included in the paper on "Trachomatous Pannus and Associated Corneal Changes" in the Trans. Ophthal. Soc., U.K., Vol. XXIV (1904), pp. 6r et seq. Thirty years ago the Transactions constituted our main means of publishing ophthalmological observations, and unfortunately their circulation abroad was very limited-evidently failing entirely to reach some of the countries where trachoma has been most widely spread.

Many of the trachomatous pits seen in Bombay were of quite low grade, certainly representing anatomical changes less advanced than those depicted by Busacca. In the darker skinned patients particularly they were thrust into prominence by an essentially and exclusively trachomatous pigmentation of the spots, that deserves more attention than it seems to have received.

The colouring was sufficiently general to justify the common designation "pigmented pits" used there. And it helped decidedly in the clinical study of pitting. It was a curious thing. Though occasionally wanting in pale skinned patients it was more often, on the other hand, excessive in proportion to the loss (apparent or real) of tissue.

For instance, in No 13 of a collection of outline drawings published with my paper (on p. 70, Trans. Ophthal. Soc., U.K. 1904, ) a number of small pigment spots are to be seen within the 
upper corneal border. In this case the central spots alone were at all depressed, and even this depression was relative only-not real. The surface level of the spots was that of the normal cornea below, contrasting with the slightly opaque level surface above and between the spots, which was raised a little by the remains of old pannus thickening.

Pigment spots along the upper corneal border never occurred in my experience entirely unassociated with some pitting there. The strength of the connecting link between the two trachomatous features-pitting and colouring-was to this degree emphasized.

On the other hand the elasticity of the link was illustrated in No. 16 of the outline drawings, above mentioned. Associated with shallow depressions in the usual position, above, there was a row of seven somewhat unevenly distributed dark spots within the lower corneal margin, all minute and sharply defined. They were smaller than the smallest pits, and placed where neither pits nor trachoma follicles are ever seen, in my experience. I do not remember any other similar cases, and have no explanation to offer.

On p. 74 of the volume referred to, the lowest recognizable grade of old pannus remains is described as a slight "extension downwards of the normal upper marginal opacity that represents overlapping sclera and conjunctiva." And in No. 12 of the collection of drawings the lower ill-defined border of such minimal inactive pannus is shown interrupted by a few "small sharply defined semicircular indentations or bays," neither depressed nor pigmented, and showing the normal corneal transparency.

To quote further from this p. 74: "In cases where the abnormal corneal opacity has extended a little further downwards, in place of these bays .... we find fully enclosed round islands, less opaque than their surroundings. On careful examination they are found to be slightly depressed below the neighbouring surface."

This barely perceptible depression was undoubtedly in many cases merely the relative pitting of my old Figs. 12 and 13, above mentioned, leaving the true corneal level practically untouched. But these minimal examples of pitting were firmly linked clinically by medium grades with the uncommon deep dark cups, depicted in a row of five, in my old Fig. 15. And it seems very probable now that among the lower and medium grade depressions there may have been cases related to Busacca's. More or less destruction of corneal lamellar tissue by trachoma nodules may have been made good by moderate downgrowth of proliferating epithelium.

The evidence that sufficed to fix the sites of the pits clearly and unmistakeably in the minimal and minor grades of pannus must be accepted also as applying definitely in the higher grades of corneal trachoma also, in which the situation of the limbus could 
no longer be made out. Though the number of the depressions varied, their site was always, so far as one could judge, the samepurely corneal, limited to a single row immediately below the site of the normal limbus.

This point needs emphasis since Busacca, in his Fig. 1 marks the lower boundary of the "lunula" well below the lower edge of the pit, instead of about its upper edge, where I think it should be marked. I took a good deal of trouble in those early days, examining a large number of upper corneal borders, both normal and otherwise, before settling this point to my own satisfaction.

There was an intriguing contrast between the very small marginal indentations of my old Fig. 12 and the corresponding isolated losses of tissue seen in the deep cups. The one seemed almost the direct negation of the other, since the sharply defined outlines and regular curves of the little indentations suggested points of especial corneal resistance to the spread of the diffuse wave of pannus. And one's natural impulse is-quite wronglyto regard the later deep excavations as indicating points of earlier special activity of the disease.

A suggested explanation is the following:-In the matter of primary onset the only known anatomical structures likely to offer especial resistance at isolated points to a superficial wave of pannus are the minute rounded basal epithelial crypts at the limbus, varying in diameter up to $1 / 7$ th millimetre (B. Graves, Brit. Jl. of Ophthal., Vol. XVIII, 1934, p. 338). The crypts are to be found in some eyes only. One can realize that deep epithelial attachments formed by the larger of these crypts may-like rocks in the bed of a stream-obstruct the downward lymph flow sufficiently to form sharply cut quiet backwaters below them, of some width, in which wandering cells may collect and multiply, forming colonies primarily superficial and flattened by the pressure of the upper lid.

The deeper pits represent the final results of long continued cellular activities as above initiated. Early follicular or nodular collections of lymphoid cells, characteristic of trachoma, have eaten their way into the corneal lamellae, and have later disappeared.

I remember seeing on two occasions only, lying at the bottom of a cup, a small defined pulpy greyish nodule or patch, which almost certainly represented the remains of lymphoid tissue. It had none of the appearance of active recuperative epithelial growth.

Such trachomatous cell collections are, of course, no more expressive of focal activities of the trachoma organism, than are the conjunctival follicles of many trivial types of conjunctivitis suggestive of focal microbial action. Yet in the destructive and cicatrizing disease alone-trachoma-are the cells able to erode 
the corneal lamellae. Hence the pitting-representing isolated losses of tissue scarcely to be compared with the extensive and obvious destruction of tissue, that may spread through the greater part of the conjunctiva.

Concerning epithelial downgrowth 'generally in these cases, I should like to suggest two possible influences:-

1. On the whole it may be accepted that there was very little indication of epithelial activity in the Indian pits. There is no doubt at all that in some cases the pits remained entirely free from epithelial accumulation. I suggest that the explanation may lie in the fact that a very large proportion of our wandering patients had had little or no previous skilled treatment of their trachoma. There had been nothing to stimulate epithelial growth.

The average trachoma case in Brazil at the present day may receive the stimulus of fairly early and regular active (? caustic) treatment. Hence possibly the epithelial response as seen in Busacca's sections:

2. If my suggestion of the origin of the pits immediately below (not beneath) basal epithelial crypts should prove to be correct, the final epithelial proliferation should vary with the size of the original crypts. The larger and deeper the crypt the freer the epithelial response.

\section{CASE OF BILATERAL EPITHELIOMA OF THE LIMBUS IN A BOY OF FIVE}

BY

\section{A. Hugh LOWTHER}

MALAYAN MEDICAL SERVICE

THE following case is worthy of record on account of the early age of onset, and of the simultaneous involvement of both eyes.

A Tamil boy, aged 5 years, first attended the Ophthalmic Department of Penang General Hospital on March 3, 1932, complaining of lacrimation, photophobia, and discharge from both eyes.

He had a severe conjunctivitis, and there was dense scarring involving practically the whole of both corneae.

The parents gave a history indicating that he had had an acute conjunctivitis four years previously, which they themselves had treated with "Nantiwalam" (a tropical flower, the juice of 